\title{
The Unit Activity of Animal Organs.
}

$\mathrm{O}^{\mathrm{N}}$

$\mathrm{NE}$ of the most remarkable features of the animal body is the fact that each organ has more substance than is necessary to do its normal amount of work. Teleologically it is easy to see that some such arrangement is necessary for successful survival, but it is more difficult to imagine the mechanism by which it is kept in working order. If a muscle is used less it grows smaller, and if it is used more it grows larger. In each case it preserves the margin of power which is known as " reserve force," despite the definite general relation between quantity of substance and quantity of function. In a recent number of the Journal of Pathology and Bacteviology (vol. xxv. p. 4I4) Dr. V. R. Khanolkar makes some interesting speculations and observations which seem to throw light on the problem, and he extends them into suggestions which may clear up some obscure points in respect of the distribution of pathological lesions in organs. So long ago as I 87 I Bowditch formulated the proposition that if the frog's heart responds at all to an artificial stimulus it responds with the greatest contraction of which the muscle is at the time capable. This principle of "all or nothing" has since been extended to other excitable tissues, most convincingly to muscle and nerve, and by implication to glands which receive their normal stimuli through the nervous system. On this basis, moderate activity of a skeletal muscle means maximal activity of a moderate number of the units, in this case muscle fibres, of which it is made up and not moderate activity of all the units.

In other words, in ordinary circumstances only a proportion of the units of any organ are active at any one time. How then do the other units escape the consequences of the rule that tissue which is not used atrophies and disappears? Marey in I885 found that the responsivity of the frog's heart to external stimuli is least when it is actually contracting and is only gradually restored to normal after the contraction is over. Each period of activity is thus followed by a "refractory period" in which the tissue will not respond to a strength of stimulus which would normally rouse it to activity, the resistance to excitation fading away until the normal excitability is regained. This refractory phase has been closely studied in nerve muscle and sense organs, and Gotch described it as a general phenomenon of living substance. In this way a rotation of activity among the units of any organ is brought about: with moderate activity in response to moderate stimulation a proportion of the units are constantly in action, but as the refractory period of each one comes on it stops working and its function is taken on by another unit with its activity more remote and its refractory period completed. As the activity of the whole organ is increased owing to stronger stimulation, the refractoriness of units is broken through first in those the activity of which is remote, next in those which have functioned more recently. Finally, with maximal stimulation all the units are forced into simultaneous action.

It seems likely that these principles, elucidated by the classical method of "wiring frogs on to machinery," are applicable to other tissues in which their demonstration is more difficult. What constitute anatomical " units" is not known. In nerve and muscle they are the individual fibres, in the central nervous system probably nerve cells, in the kidney. possibly the glomerular-tubal systems, in glands apparently groups of adjacent cells-but they might be parts of organs, cells, or even parts of cells. Dr. Khanolkar has specially concerned himself with the kidney, and supposing that each glomerulus with its efferent tubule is a unit, points out that the hypothesis would explain the irregular distribution of the lesions in the common chronic degeneration of that organ. Assuming that the original injury is due to some poison circulating in the blood, it follows that more of it will reach active than passive units since activity is always associated with a local increase in blood supply. On general grounds also it is quite likely that functioning cells are more reactive and hence more easily poisoned than cells at rest. In chronic general nephritis some glomeruli are destroyed while others appear to escape injury altogether, and the diseased and healthy units are found scattered uniformly all over the organ. It is suggested that the injured units are those which happened to be active when a toxic concentration of the poison was in the blood. Extending the idea to other organs, it follows that activity always renders a tissue more susceptible to poisonous substances, which may be the explanation of why the parts of the nervous system most constantly in heavy use are specially liable to suffer in general lead poisoning and other similar relations. Failure of an organ from over use might in part be due to this, in part to the absence of rest for any of the units. It is well recognised that hypertrophy of skeletal muscle is best secured by exercises which seem absurdly mild : on the hypothesis of unit activity it is easy to understand why light dumb-bells should keep more units in the best possible condition than heavy ones.

Dr. Khanolkar adduces experimental evidence that in the kidney during moderate activity only some of the glomeruli are in action, while more or all will excrete actively when the organ is strongly stimulated with diuretics. Incidental observations on the adrenal medulla, pituitary, pancreas, and salivary glands give histological evidence of the same partial activity. The whole fits in well with Krogh's recent demonstration that many capillaries in normal organs are at any one moment closed and out.of action.

\section{Climates of the Past.}

W. R. ECKARDT, of Essen, has contributed a memoir," Paläoklimatologie, ihre Methoden und ihre Andwendung auf die Paläobiologie," to Prof. Abderhalden's comprehensive "Handbuch der biologischen Arbeitsmethoden" (Urban und Schwarzenberg, Berlin), of which it forms Heft 3 of Abteilung Io. It is written in what may be called the über Alles type of German, without much consideration for the southerner or the stranger, and sentences containing more than roo words are not uncommon. It embodies, however, a valuable and critical review of the way in which various classes of geological evidence may be used as indications of the climatic environment of the faunas and floras of the past.

The character and colour of fossil soils are discussed by Dr. Eckardt, equally with the distribution of 